\title{
Flourishing in Young Adults: The Role of Achievement Goals, Participation Motivation, and Self-Perception Levels in Physical Activity Contexts
}

\author{
Zişan Kazak $^{1, * \mathbb{D}}$, Marc Lochbaum ${ }^{2,3}$ (D) and Ayşe Meliha Canpolat ${ }^{1}$ \\ 1 Faculty of Sport Science, Ege University, Bornova, Izmir 35100, Turkey; monursal@yahoo.com \\ 2 Department of Kinesiology \& Sport Management, Texas Tech University, Lubbock, TX 79409, USA; \\ marc.lochbaum@ttu.edu \\ 3 Education Academy, Vytautas Magnus University, 44248 Kaunas, Lithuania \\ * Correspondence: f.zisan.kazak@ege.edu.tr
}

check for

updates

Citation: Kazak, Z.; Lochbaum, M.; Canpolat, A.M. Flourishing in Young Adults: The Role of Achievement Goals, Participation Motivation, and Self-Perception Levels in Physical Activity Contexts. Sustainability 2021, 13, 7450. https://doi.org/10.3390/ su13137450

Academic Editors: Jürgen Beckmann and Sidonio Serpa

Received: 25 May 2021

Accepted: 29 June 2021

Published: 2 July 2021

Publisher's Note: MDPI stays neutral with regard to jurisdictional claims in published maps and institutional affiliations.

Copyright: (c) 2021 by the authors. Licensee MDPI, Basel, Switzerland. This article is an open access article distributed under the terms and conditions of the Creative Commons Attribution (CC BY) license (https:// creativecommons.org/licenses/by/ $4.0 /)$.

\begin{abstract}
This study aims to determine how achievement goals, participation motivation and selfperception levels in physical activity environments relate to the flourishing of young adults. The general purpose of the study was also to examine differences in selected variables of young adults flourishing in physical activity environments. To achieve our aims, the recruited sample consisted of 580 young adult exercisers ranging in age from 18 to 40 years from fitness centers in Izmir, Turkey. Participants completed a personal information form, the Flourishing Scale, the $2 \times 2$ Achievement Goals Questionnaire for Sport $(2 \times 2$ AGQ-S), the Situational Motivation Scale (SIMS), and the Physical Self-Description Questionnaire (PSDQ). We examined correlations, regressions, and path models with our measured variables. Flourishing relates significantly $(p<0.001)$ and positively with global self-esteem, the mastery-approach goal, intrinsic motivation, and global physical selfconcept. Our path model suggested that the mastery-approach goal, intrinsic motivation, and global self-esteem partially mediated the relationship between global physical self-concept and flourishing. Our findings help to inform alternative approaches for cultivating exercisers' flourishing. However, knowledge on how to support and develop flourishing is still under-researched in sport and exercise settings.
\end{abstract}

Keywords: flourishing; achievement goals; motivation; self-perception

\section{Introduction}

Positive psychology considers personal strengths and psychological resources as basic elements that contribute to well-being and flourishing [1]. Thus, in recent years, positive psychology focuses on a broader term of well-being, now called as flourishing. Flourishing is a positive mental health construct regarding emotional, psychological, and social wellbeing [2] and a multidimensional index of well-being [3]. Flourishing is the combination of psychological and subjective well-being [4]. Fredrickson and Losada [5] have defined flourishing as within an optimal range of human functioning, one that connotes goodness, generativity, growth, and resilience. Flourishing individuals have excellent emotional health, enthusiasm for life, and engage actively and efficiently with other people and in society [6]. Low and moderate well-being is highly prevalent in the USA and Europe [7-9]. Only $20 \%$ of adults fit the criteria for flourishing in life [9]. According to the 23 countries' data that participated in the European Social Survey, it has been revealed a four-fold difference in flourishing rate, from $41 \%$ in Denmark to less than $10 \%$ in Slovakia, Russia, and Portugal [7].

Different areas of life (e.g., work, family, exercise) influence flourishing. Each individual's relative successes achieved in different fields, like sport and academic career, during their lifetime closely relate to their flourishing experience [10]. It is a fact that participation 
in sport and physical activity can foster flourishing, positive experiences, positive emotions besides health at all age levels. Sport researchers demonstrated sport participation associates with optimal levels of well-being and other positive outcomes (e.g., [11]). Exercising regularly often leads to positive results such as high-performance levels and psychological well-being and can lead athletes to increase their skills, and consequently, their feelings of competence [11]. Physical activity settings can play a supporting role in increasing the number of flourishing individuals in the population. Indeed, in general, flourishing for athletes consists of positive feelings and emotional states, and the fulfillment of needs [10].

\subsection{Motivation Theories, Self-Esteem and Flourishing}

Kaplan and Maehr [12] suggested that different achievement goals a person adopts might affect processes relating (to) well-being and found that the pursuit of mastery goals positively relates with general indices of well-being. Duda [13] has also suggested that variations in achievement goals provide insight into variability in sport participants' psychological and emotional well-being. Some researchers [14] have reported in their studies that mastery-approach and mastery-avoidance goal orientation positively predicted flourishing, and flourishing related positively to the mastery-approach, mastery-avoidance, and performance-approach goals. In this study, moderation occurred by achievement domains concerning the relation between mastery-avoidance goal orientation and well-being. In another study, Datu, Labarda, and Salanga [15] found flourishing positively associated with mastery-approach goals, mastery-avoidance goals, performance-approach goals, and performance-avoidance goals. Howell [16] demonstrated that flourishing positively correlated to mastery-approach goals. Elliot and Sheldon [17] showed that avoidance goals negatively relate to subjective well-being. Recently, van Dam, Noordzij and Born [14] reported the mastery goal orientation contributed directly to flourishing. Last, in their meta-analysis, Lochbaum, Zanatta, and Kazak [18] reported that the mastery-approach related positively to positive outcomes such as relative autonomy, intrinsic motivation, positive affect, and effort that were associated with flourishing.

Self-determination theory (SDT) is a macro theory that includes human motivation, personality development, and well-being [19] and proposes that autonomous selfregulation leads to increased well-being. The theory has different motivation styles that vary in terms of their degree of self-determination (e.g., intrinsic motivation, integrated regulation, identified regulation, introjected regulation, external regulation, amotivation). Intrinsic motivation, characterized by a high degree of autonomy, plays an important role in well-being $[20,21]$. Some research has focused on the benefits of intrinsic motivation on factors such as well-being. Intrinsic motivation relates to well-being [22,23]. Autonomous motivation styles correlate positively with well-being and intrinsic motivation and are better predictors than identified regulation. Moreover, Gagne [24] demonstrated other motivational styles did not associate with changes in well-being. Sheldon and Kasser [25] found well-being increases with the achievement of intrinsic goals, but success in extrinsic goals causes little well-being. Unquestionably, intrinsic motivation has more positive effects on well-being than extrinsic motives, and that external motivation causes a decrease in well-being [26]. Papaioannou and Krommidas [27] have reported that flourishing positively related to intrinsic motivation and identified regulation, and negatively related to external regulation and amotivation.

Like mastery-approach goal and intrinsic motivation, self-esteem is a key indicator of psychological well-being [28]. Diener et al. [3] addressed flourishing as a multidimensional framework that individuals view themselves in positive terms in important areas of functioning such as relationships, self-esteem, purpose, and optimism. Furthermore, studies have revealed that self-esteem has some positive effects on well-being [29] and that there is an association between self-esteem and subjective well-being [30,31]. Dogan, Totan, and Sapmaz [32] have determined a positive and significant relationship between psychological well-being and self-esteem. Lin [33] has revealed that higher levels of self-esteem associate with indices of well-being. Further, researchers $[29,34]$ reported that self-esteem is 
a significant predictor of psychosocial flourishing. Li et al. [35] have found that self-esteem positively correlated with psychosocial flourishing.

\subsection{Study Aim}

The young adulthood period is a difficult process to manage, especially with the acquisition of new roles, and responsibilities that increase even more in this period. The difficulties that individuals will encounter in this process can create situations that affect the pleasure, satisfaction, and emotions they get from life and, accordingly, their mood in life. Information about how the activities individuals participate to improve their lives to affect their mood, how these moods differ in the relevant environments, and what one does needs to create a positive mood is important to increase the quality of life and general well-being. Keyes [2] suggested that flourishing decreases in adulthood. In summary, we need more research to understand the antecedents of optimal functioning to enhance individuals flourishing. To date, only Kazak and Lochbaum [36] carried out a study to explain whether the satisfaction of the three basic psychological needs results in different psychological health indices (flourishing, positive and negative affect, and relative autonomy) in exercise contexts. There is not enough research focused on total well-being, known as flourishing in the sports setting. In this study, we try to determine how achievement goals, participation motivation, and self-perception levels in physical activity environments related to the flourishing (i.e., well-being) of young adults.

\section{Materials and Methods}

\subsection{Participants}

The sample consisted of 580 young adult exercisers attending different sport centers in Izmir, Turkey (female $=217$, male $=363$ ). Participants ranged in age from 18 to 40 years (mean age $25.93 \pm 5.99$ ). Participants self-reported being $175.79 \pm 9.64 \mathrm{~cm}$ in height and $73.41 \pm 14.47 \mathrm{~kg}$ in weight. Based on participant height and weight values, the mean sample body mass index was $23.60 \pm 3.44 \mathrm{~kg} / \mathrm{m}^{2}$. Concerning weekly self-reported exercise, participants reported the mean exercise duration was $87.39 \pm 33.65 \mathrm{~min}$ across $4.18 \pm 1.34$ days a week. Last, for our collected participant characteristics, they reported participating in sport for $7.21 \pm 6.21$ years.

\subsection{Measures}

\subsubsection{Flourishing Scale}

Developed by Diener et al. [3] and translated into the Turkish literature by Telef [37], the Flourishing Scale (FS) consists of eight items (e.g., "I actively contribute to the happiness and well-being of others") measuring the psychological construct termed flourishing. To complete the measure, participants rated each item on a Likert scale ranging from 1 (strongly disagree) to 7 (strongly agree). The total score may range between 8 and 56. Based on Telef's [37] translation work, the validity, and reliability information of the scale was acceptable. For instance, exploratory factor analysis results indicated that the total variance explained was $42 \%$. The factor loads of the scale items vary between 0.54 and 0.76 . The Cronbach alpha internal consistency coefficient obtained in the reliability study of the scale was 0.80 . The scale's test-retest reliability was 0.86 . Last, Telef [37] reported the item-total correlations of the scale varied between 0.41 and 0.63 . In this investigation, the Cronbach coefficient of internal consistency was 0.88 .

\subsubsection{The $2 \times 2$ Achievement Goals Questionnaire for Sport}

The $2 \times 2$ Achievement Goals Questionnaire for Sport (AGQ-S; [38]) assessed exercisers' approach-avoidance achievement goals. Kazak Çetinkalp [39] translated the $2 \times 2$ AGQ-S into Turkish. The questionnaire consists of 12 items and measures the following achievement goals: mastery-approach (MAp, e.g., "I want to perform as well as it is possible for me to perform"), mastery-avoidance (MAv, e.g., "Sometimes I'm afraid that I may not perform as well as I'd like"), performance-approach (PAp, e.g., "My goal is to do 
better than most other performers"), and performance-avoidance (PAv, e.g., "It is important for me to avoid being one of the worst performers in the group). In this study, "At the sports center..." was the questionnaire stem. Participants rated their agreement with the statements using a Likert-type scale from 1 (strongly disagree) to 7 (strongly agree). In her translation work, Kazak Çetinkalp [39] reported acceptable construct validity and internal reliability values. In this study, Cronbach's internal consistency coefficients were 0.81 for MAp, 0.81 for MAv, 0.86 for PAp, and 0.73 for PAv.

\subsubsection{The Situational Motivation Scale}

The Situational Motivation Scale (SIMS) measured participants' situational motivation. The scale is a 16-item self-report inventory developed by Guay, Vallerand, and Blanchard [40] and translated into Turkish by Kazak Çetinkalp [41]. The scale measures intrinsic motivation (e.g., "Because this activity is fun"), identified regulation (e.g., "Because I think that this activity is good for me"), external regulation (e.g., "Because it is something that I have to do"), and amotivation (e.g., "I do this activity, but I am not sure if it is worth it"). The participants responded on a seven-point Likert-type scale, ranging from 1 (Strongly disagree) to 7 (Strongly agree). The SIMS is a valid and reliable measure of exercisers' situational motivation in exercise settings [41]. The fit index values, calculated for the adaptation of the model, were well fit. Cronbach's alpha coefficients were 0.79, $0.73,0.77$, and 0.79 for intrinsic motivation, identified regulation, external regulation, and amotivation, respectively. In this study, the internal consistency coefficients were 0.84 for intrinsic motivation, 0.86 for identified regulation, 0.75 for external regulation, and 0.84 for amotivation.

\subsubsection{The Physical Self-Description Questionnaire}

The Physical Self-Description Questionnaire (PSDQ), developed by Marsh et al. [42] and translated into Turkish by Aşçı [43], assesses individual self-perceptions, specifically physical self-perception. It is a 70-item instrument designed to measure the following 11 scales: Health, coordination, activity, body fat, sports competence, appearance, strength, flexibility, endurance and fitness, global physical self-concept, and global self-esteem. In this study, we used only the global physical self-concept (e.g., "I am satisfied with the kind of person I am physically") and global self-esteem (e.g., "Overall, most things I do turn out well") subscales. Participants responded on a six-point Likert scale $(1=$ false and $6=$ true). The factor structure of the PSDQ was also supported [43]. In the latter, a crosscultural validity study has indicated acceptable goodness of fit indices of PSDQ for Turkish university students. Cronbach's alpha coefficients were 0.90 for global physical self-concept and 0.80 for global self-esteem [44]. In the present study, Cronbach's $\alpha$ coefficients were 0.88 for global physical self-concept and 0.81 for global self-esteem.

\subsection{Procedure}

The first and third authors collected the data at sports / fitness centers and exercise studios in Izmir after the researchers obtained permission from the Ege University Scientific Research and Publication Ethics Committee's (EGEBAYEK) Approval no: 20.12.2018-12/1480. Potential participants received verbal and written materials about the study in question and ensured confidentiality. All potential male and female volunteer exercise participants received and signed an informed consent form to follow the Declaration of Helsinki. Participants completed the questionnaire package in a room with the tables and chairs provided before participating in their fitness activities. Participants completed the questionnaire within 15-20 min. Data collection occurred every day of the week. Ege University Scientific Research Projects Coordination Unit (Project Number: SGA-2019-20244) supported this study. 


\subsection{Data Analysis}

All data analyses occurred within IBM SPSS Statistics (v. 20) and LISREL 8.54. All subscales were scored, a check for outliers occurred. We defined outliers as standardized residual values above -3 and +3 . We deleted the outlying values. Before our main analyses, we examined our data with descriptive and correlations. Turning to our main research questions, we used multiple regression analysis with stepwise method and path analysis to examine the association of flourishing with mastery-approach, mastery-avoidance, performance-approach, performance-avoidance, intrinsic motivation, identified regulation, external regulation, amotivation, global physical self-concept, and global self-esteem. In the path analysis, the Standardized Root Mean Square Residual (SRMR), the Adjusted Goodness of Fit Index (AGFI), the Comparative Fit Index (CFI), the Tucker-Lewis Index (TLI), and Root Mean Square Error of Approximation (RMSEA) assessed model fit. Bentler and Bonett [45] recommended that TLI values greater than 0.90 indicate an acceptable fit. AGFI values greater than 0.85 are an acceptable fit. CFI values greater than 0.95 may be an acceptable fit. SRMR values close to or less than 0.05 indicate a good fit. RMSEA value greater than 0.10 is considered unacceptable, and values up to 0.05 indicate a good fit [46].

\section{Results}

\subsection{Descriptive Statistics and Correlations}

Table 1 contains the descriptive statistics and correlations among the study variables. These descriptive statistics for the entire sample revealed above-average and high values of flourishing $(\mathrm{M}=45.89 ; \mathrm{SD}=7.82)$, mastery-approach $(\mathrm{M}=6.22 ; \mathrm{SD}=0.89)$, performanceapproach $(M=5.16 ; S D=1.58)$, intrinsic motivation $(M=5.63 ; S D=1.34)$, identified regulation $(\mathrm{M}=5.89 ; \mathrm{SD}=1.23)$, global physical self-concept $(\mathrm{M}=4.67 ; \mathrm{SD}=0.97)$, and global self-esteem $(\mathrm{M}=4.64 ; \mathrm{SD}=0.89)$. In contrast, the scores for mastery-avoidance $(\mathrm{M}=4.33 ; \mathrm{SD}=1.64)$, performance-avoidance $(\mathrm{M}=4.52 ; \mathrm{SD}=1.59)$, extrinsic regulation $(\mathrm{M}=3.64 ; \mathrm{SD}=1.49)$ were moderate. Lower values resulted for amotivation score $(\mathrm{M}=2.64$; $\mathrm{SD}=1.56)$.

Table 1. Descriptive statistics and correlations between all variables of the overall sample.

\begin{tabular}{|c|c|c|c|c|c|c|c|c|c|c|c|c|}
\hline & $\mathbf{M}$ & SD & 1 & 2 & 3 & 4 & 5 & 6 & 7 & 8 & 9 & 10 \\
\hline 1. Flourishing & 45.89 & 7.82 & 1 & & & & & & & & & \\
\hline 2. MAp & 6.22 & 0.89 & $0.35^{* *}$ & 1 & & & & & & & & \\
\hline 3. MAv & 4.33 & 1.64 & -0.01 & $0.14^{* *}$ & 1 & & & & & & & \\
\hline 4. PAp & 5.16 & 1.58 & 0.03 & $0.34 * *$ & $0.37^{* *}$ & 1 & & & & & & \\
\hline 5. PAv & 4.52 & 1.59 & 0.04 & $0.22 * *$ & $0.52 * *$ & $0.69^{* *}$ & 1 & & & & & \\
\hline 6. IM & 5.63 & 1.34 & $0.22^{* *}$ & $0.28^{* *}$ & 0.03 & 0.07 & 0.06 & 1 & & & & \\
\hline 7. IR & 5.89 & 1.23 & $0.22^{* *}$ & $0.29 * *$ & -0.00 & 0.03 & -0.02 & $0.72 * *$ & 1 & & & \\
\hline 8. ER & 3.64 & 1.49 & -0.08 & -0.11 & 0.13 & $0.15^{* *}$ & $0.21^{* *}$ & -0.02 & 0.03 & 1 & & \\
\hline 9. A & 2.64 & 1.56 & $-0.22 * *$ & $-0.24^{* *}$ & 0.09 & 0.09 & $0.14^{* *}$ & $-0.22^{* *}$ & $-0.39 * *$ & $0.44^{* *}$ & 1 & \\
\hline 10. GPSC & 4.67 & 0.97 & $0.29 * *$ & $0.29 * *$ & -0.12 & 0.06 & 0.03 & $0.21 * *$ & $0.24^{* *}$ & -0.08 & $-0.19 * *$ & 1 \\
\hline 11. GSE & 4.64 & 0.89 & $0.39^{* *}$ & $0.34^{* *}$ & $-0.25^{* *}$ & -0.10 & $-0.16^{* *}$ & $0.20 * *$ & $0.33^{* *}$ & $-0.25 * *$ & $-0.45^{* *}$ & $0.47^{* *}$ \\
\hline
\end{tabular}

Note: ${ }^{* *} p<0.001 ;$ M: Mean; SD: Standard deviation; MAp: mastery-approach; MAv: mastery-avoidance; PAp: performance-approach; PAv: performance-avoidance; IM: intrinsic motivation; IR: identified regulation; ER: external regulation; A: amotivation; GPSC: global physical self-concept; GSE: global self-esteem.

We evaluated the variable relationships by examining Pearson correlations on our 580 participants. The Bonferroni $p$ to control for type I error, we use the Bonferroni correction method. For 55 correlations, the Bonferroni $p$ is $0.05 / 55=0.001$. Hence, we evaluated significance on the adjusted value. Concerning the correlations, flourishing related significantly to mastery-approach goal $(\mathrm{r}=0.35 ; p<0.001)$, intrinsic motivation $(\mathrm{r}=0.22 ; p<0.001)$, identified regulation $(\mathrm{r}=0.22 ; p<0.001)$, amotivation $(\mathrm{r}=-0.22$; $p<0.001)$, global physical self-concept $(\mathrm{r}=0.29 ; p<0.001)$, and global self-esteem $(\mathrm{r}=0.39$; $p<0.001)$. 


\subsection{Regression Analysis}

Stepwise multiple regression analysis examined the association of flourishing with achievement goals (mastery-approach, mastery-avoidance, performance-approach, performance-avoidance), participation motivation (intrinsic motivation, identified regulation, external regulation, amotivation), and self-perception levels (global physical self-concept, global self-esteem). Only global self-esteem, mastery-approach goal, intrinsic motivation, and global physical self-concept predicted flourishing $\left(\mathrm{F}_{(4,575)}=39.73\right.$; $p<0.001)$. Multiple $\mathrm{R}$ is 0.47 , indicating a significant correlation between the predictor variables and the dependent variable. The predictor variables explained $22 \%$ of the variance in flourishing (15\% global self-esteem, $5 \%$ mastery-approach goal, $1 \%$ intrinsic motivation, and $1 \%$ global physical self-concept). When examined the $\beta$ values indicating the relative influence of the entered variables, global self-esteem has the greatest influence on flourishing $(\beta=0.25)$, followed by mastery-approach $(\beta=0.21)$ and global physical self-concept $(\beta=0.10)$ and then intrinsic motivation $(\beta=0.09)$. The direction of influence for all three is positive (see Table 2).

Table 2. Summary of stepwise multiple regression analysis predicting flourishing scores.

\begin{tabular}{cccccc}
\hline & B & SE & $\boldsymbol{\beta}$ & $\mathbf{t}$ & $\boldsymbol{p}$ \\
\hline Constant & 30.17 & 1.59 & & 18.88 & 0.000 \\
GSE & 3.39 & 0.34 & 0.39 & 10.02 & 0.000 \\
\hline Constant & 20.39 & 2.23 & & 9.15 & 0.000 \\
GSE & 2.66 & 0.35 & 0.30 & 7.63 & 0.000 \\
MAp & 2.11 & 0.35 & 0.24 & 6.09 & 0.000 \\
\hline Constant & 18.99 & 2.28 & & 8.32 & 0.000 \\
GSE & 2.25 & 0.38 & 0.26 & 5.92 & 0.000 \\
MAp & 1.97 & 0.35 & 0.23 & 5.63 & 0.000 \\
GPSC & 0.90 & 0.34 & 0.11 & 2.63 & 0.009 \\
\hline Constant & 17.74 & 2.34 & & 7.59 & 0.000 \\
GSE & 2.19 & 0.38 & 0.25 & 5.78 & 0.000 \\
MAp & 1.79 & 0.36 & 0.21 & 5.04 & 0.000 \\
GPSC & 0.82 & 0.34 & 0.10 & 2.38 & 0.018 \\
IM & 0.53 & 0.23 & 0.09 & 2.34 & 0.019 \\
\hline
\end{tabular}

Note. MAp: mastery-approach; IM: intrinsic motivation; GPSC: global physical self-concept; GSE: global selfesteem. $R^{2}$ for GSE $=0.15 ; R^{2}$ for Map $=0.05 ; R^{2}$ for GPSC $=0.01 ; R^{2}$ for $I M=0.01$.

\subsection{Path Analysis}

To determine whether athletes' self-perceptions, participation motivation, and achievement goals had a direct and indirect effect on flourishing, we used path analysis. We tested a model that included additional direct paths between achievement goals and flourishing, between self-perceptions and flourishing, and between participation motivation and flourishing. When the direct effect of achievement goals, motivation, and self-perception levels on flourishing are examined separately, mastery-approach goal, performance-approach goal, intrinsic motivation, amotivation, global physical self-concept, and global self-esteem had a direct effect on flourishing. The mastery-approach goal, intrinsic motivation, global physical self-concept, and global self-esteem related positively to flourishing ( $\beta=0.38$, $\beta=0.18, \beta=0.15, \beta=0.31$, respectively). The performance-approach goal and amotivation related negatively to flourishing $(\beta=-0.09, \beta=-0.18$, respectively).

We tested a revised model with variables with significant direct effects. This model has included one exogenous variable (global physical self-concept), three mediator variables (mastery-approach, intrinsic motivation, global self-esteem, performance-approach goal, and amotivation), and one endogenous variable (flourishing). We excluded the performance-approach goal and amotivation pathways from the model because they were not significant. Then, we retested the model (Figure 1). The mastery-approach goal $(\beta=0.22 ; t=5.39)$, intrinsic motivation $(\beta=0.10 ; t=2.60)$, and global self-esteem $(\beta=0.29$; $t=7.31$ ) related positively to flourishing. Our path model demonstrated acceptable fit 
$\left(\chi^{2}=5.64, \mathrm{df}=1, p=0.02, \mathrm{SRMR}=0.02\right.$ AGFI $\left.=0.94, \mathrm{CFI}=0.99, \mathrm{TLI}=0.90, \mathrm{RMSEA}=0.09\right)$. The mastery-approach goal, intrinsic motivation, and global self-esteem partially mediated the relationship between global physical self-concept and flourishing. The results in the alternative model showed that the direct effects were a bit higher than the total effects, suggesting mediating (i.e., indirect) effects.

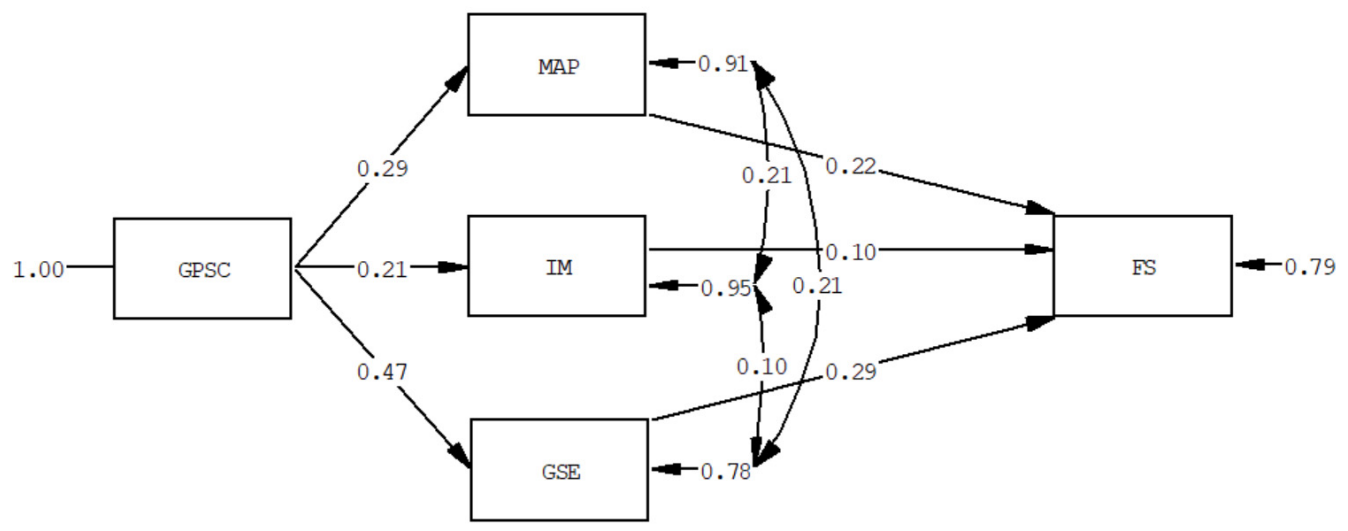

Figure 1. Path analysis among achievement goals, motivation types, self-perceptions, and flourishing.

\section{Discussion}

The aim of this study was to determine how achievement goals, participation motivation, and self-perception levels in physical activity environments relate to young adult self-rated flourishing. Flourishing related significantly to the mastery-approach goal, intrinsic motivation, identified regulation, amotivation, global physical self-concept, and global self-esteem. We also tried to determine whether athletes' self-perceptions and achievement goals had a direct and indirect effect on flourishing or not. The path analysis results demonstrated, global self-esteem, mastery-approach, intrinsic motivation, and global physical self-concept related to flourishing. These results are consistent with previous research. The information in the literature shows that approach goal orientations are more adaptive than avoidance goal orientations [47]. For example, mastery-approach goals positively associate with intrinsic motivation, positive affect, satisfaction, effort, and well-being [18,48]. Especially, Howell [16] suggested that mastery-approach goals should be more systematically associated with well-being than other goal orientations. Studies are also showing that flourishing is positively associated with mastery-approach goals (e.g., [16]). Datu, Labarda, and Salanga [15] reported that flourishing was associated with a higher level of masteryapproach goals. In addition, their study, unlike our findings, indicated flourishing also linked to a higher degree of performance approach, mastery-avoidance, and performanceavoidance goals. In another study, a mastery goal orientation contributed directly to flourishing [14]. Adie, Duda, and Ntoumanis [49] have found that mastery approach goal and mastery avoidance goal relate positively to self-esteem. Tuominen-Soini, Salmela-Aro, and Niemivirta [50] found that performance-avoidance orientation negatively relates to self-esteem. Kavussanu and Harnisch [51] found that youth sport participants who have high task orientation exhibited significantly higher self-esteem. Payne, Youngcourt, and Beaubien [52] indicated that self-esteem positively correlated with mastery-approach goals and negatively associated with performance goals. In the light of these studies, mastery goals are related to self-perception and flourishing, and this relation is the expected result.

Well-being has an important place in self-determination theory, as one achieves psychological well-being by the satisfaction of basic needs. Factors affecting the satisfaction of these needs affect well-being and decrease or increase accordingly. The main reason for this is the satisfaction of these basic needs affects organismic processes such as intrinsic motivation and the internalization of extrinsic motivation [53]. In this study, we revealed that there is a relationship between intrinsic motivation and flourishing. This result seems to be consistent with the information in the literature. Some studies in the literature (e.g., [27]) support the positive relationship between flourishing and intrinsic motivation. Well-being 
is a complex structure related to optimal experience and functionality, and indicators of well-being should be positively related to the intrinsic motivations of individuals [54,55]. González Olivares and colleagues [56] analyzed the relative influence of the different intrinsic motivation factors on psychological well-being with a linear regression analysis. They found that interest/enjoyment, which correlates with intrinsic motivation, has the greatest influence on well-being, and all dimensions of well-being correlate positively with intrinsic motivation.

When examined in general, the studies on motivation in the literature overwhelmingly suggest a positive relationship between intrinsic motivation and well-being. Weinstein and Ryan [57] determined that individuals with higher controlled motivation compared to individuals with more autonomous motivation reported significantly lower well-being. Sheldon et al. [58] revealed that autonomous motivation has a positive relationship with well-being; however, controlled motivation has a negative relationship with well-being. Intrinsic motivation has also been largely associated with self-esteem [59]. Behaviors performed for autonomous reasons (e.g., intrinsic motivation) are the type of behaviors that satisfy psychological needs. Researchers [60] point out that such behaviors lead to positive outcomes such as self-esteem [60]. Kernis et al. [61] found self-esteem positively correlates with intrinsic motivation. Wilson and Rodgers [62], in their study evaluating the relationship between exercise motives and physical self-esteem in female exercise participants, determined more autonomous motives positively related to physical selfesteem. Considering all these study results, the role of self-perception in the relationship between intrinsic motivation and development appears to be consistent with the literature.

Studies provide evidence that psychological well-being and self-esteem relate [32,63]. Rosenberg [64] has defined self-esteem or global self-esteem as the emotional evaluation individuals make about themselves. Fox [65] has noted that self-esteem characterizes emotional stability and adjustment and relates to well-being indices. The model of selfperception proposed by Shavelson, Hubner, and Stanton [66] expressed that global selfesteem sits at the top of the self-perception hierarchy and represents an omnibus indicator of psychological well-being. It is pointed out that self-concept is crucial to psychological well-being and facilitates other important aspects of psychological well-being including happiness, motivation, and academic striving behaviors [67]. Self-esteem relates to wellbeing because it provides superior and self-confident feelings [68].

The current study has limitations. Our study relied exclusively on cross-sectional self-report data. We assumed participants answered honestly. In the future, researchers should examine these variables using longitudinal methods and objective physical activity measures to validate our findings. We did not evaluate the importance of exercise group types. Future research may provide a different perspective by examining individuals in different exercise groups, such as individual activities compared to team activities. Age was another limitation in this study. Our participants' ages ranged between 18 and 40 years. Perhaps flourishing and our variables differ across the lifespan.

\section{Conclusions}

Even with our stated limitations, our findings indicate the importance of achievement goals and self-perceptions. Our findings can help to inform alternative approaches for cultivating exercisers' flourishing. Flourishing in sport and exercise settings is more popular in recent years; however, knowledge on how to support and develop flourishing is still under-researched in sport and exercise settings.

Author Contributions: Conceptualization, Z.K., M.L. and A.M.C.; methodology, Z.K., M.L. and A.M.C.; formal analysis, Z.K.; investigation, Z.K., M.L. and A.M.C.; resources, Z.K., M.L. and A.M.C.; writing—original draft preparation, Z.K., M.L. and A.M.C.; writing-review and editing, Z.K. and M.L.; visualization, Z.K.; supervision, Z.K. and M.L. All authors have read and agreed to the published version of the manuscript. 
Funding: Ege University Scientific Research Projects Coordination Unit (Project Number: SGA-201920244) supported this study.

Institutional Review Board Statement: The researchers obtained permission from the Ege University Scientific Research and Publication Ethics Committee's (EGEBAYEK) Approval no: 20.12.2018-12/14-80.

Informed Consent Statement: Informed consent was obtained from all subjects involved in the study.

Data Availability Statement: Data sharing not applicable.

Conflicts of Interest: The author declares no conflict of interest.

\section{References}

1. Peter, C.; Geyh, S.; Ehde, D.M.; Müller, R.; Jensen, M.P. Positive Psychology in Rehabilitation Psychology Research and Practice. In Positive Psychology in Practice: Promoting Human Flourishing in Work, Health, Education, and Everyday Life; Joseph, S., Ed.; John Wiley \& Sons, Inc.: Hoboken, NJ, USA, 2015; pp. 443-459.

2. Keyes, C.L.M. The mental health continuum: From languishing to flourishing in life. J. Health Soc. Behavior. 2002, 43, 207-222. [CrossRef]

3. Diener, E.; Wirtz, D.; Tov, W.; Kim-Prieto, C.; Choi, D.W.; Oishi, S.; Biswas-Diener, R. New well-being measures: Short scales to assess flourishing and positive and negative feelings. Soc. Indic. Res. 2010, 97, 143-156. [CrossRef]

4. Pozo, C.; Garzón, A.; Charry, C.; Bretones, B. Psychometric properties and dimensionality of the "Flourishing Scale" in Spanishspeaking population. Electr. J. Res. Educ. Psychol. 2016, 14, 175-192. [CrossRef]

5. Fredrickson, B.L.; Losada, M.F. Positive affect and the complex dynamics of human flourishing. Am. Psychol. 2005, 60, 678-686. [CrossRef]

6. Keyes, C.L.M. Complete mental health: An agenda for the 21st century. In Flourishing: Positive Psychology and the Life Well-Lived; Keyes, C.L.M., Haidt, J., Eds.; American Psychological Association: Washington, DC, USA, 2003; pp. $293-312$.

7. Huppert, F.A.; So, T.T.C. Flourishing across Europe: Application of a new conceptual framework for defining well-being. Soc. Indic. Res. 2013, 110, 837-861. [CrossRef] [PubMed]

8. Keyes, C.L.M. Mental illness and/or mental health? Investigating axioms of the complete state model of health. J. Consult. Clin. Psychol. 2005, 73, 539-548. [CrossRef] [PubMed]

9. Keyes, C.L.M. Promoting and protecting mental health as flourishing: A complementary strategy for improving national mental health. Am. Psychol. 2007, 62, 95-108. [CrossRef] [PubMed]

10. Ashfield, A.; McKenna, J.; Backhouse, S. The athlete's experience of flourishing. Qual. Methods Psychol. Bull. 2012, $14,4-13$.

11. Verner-Filion, J.; Vallerand, R.J.; Amiot, C.E.; Mocanu, I. The two roads from passion to sport performance and psychological well-being: The mediating role of need satisfaction, deliberate practice, and achievement goals. Psychol. Sport Exerc. 2017, 30, 19-29. [CrossRef]

12. Kaplan, A.; Maehr, M.L. Achievement goals and student well-being. Contemp. Educ. Psychol. 1999, 24, 330-358. [CrossRef]

13. Duda, J.L. Achievement goal research in sport: Pushing the boundaries and clarifying some misunderstandings. In Advances in Motivation in Sport and Exercise; Roberts, G.C., Ed.; Human Kinetics: Champaign, IL, USA, 2001; pp. $129-182$.

14. van Dam, A.; Noordzij, G.; Born, M. Thriving under uncertainty: The effect of achievement goal orientation on job insecurity and flourishing. Soc. Indic. Res. 2020, 150, 659-678. [CrossRef]

15. Datu, J.A.D.; Labarda, C.E.; Salanga, M.G.C. Flourishing is associated with achievement goal orientations and academic delay of gratification in a collectivist context. J. Happiness Stud. 2020, 21, 1171-1182. [CrossRef]

16. Howell, A.J. Flourishing: Achievement-related correlates of students' well-being. J. Posit. Psychol. 2009, 4, 1-13. [CrossRef]

17. Elliot, A.J.; Sheldon, K.M. Avoidance achievement motivation: A personal goals analysis. J. Personal. Soc. Psychol. 1997, 73, 171-185. [CrossRef]

18. Lochbaum, M.; Zanatta, T.; Kazak, Z. The $2 \times 2$ achievement goals in sport and physical activity contexts: A meta-analytic test of context, gender, culture, and socioeconomic status differences and analysis of motivations, regulations, affect, effort, and physical activity correlates. Eur. J. Investig. Health Psychol. Educ. 2020, 10, 173-205. [CrossRef]

19. Deci, E.L.; Ryan, R.M. Self-determination theory: A macrotheory of human motivation, development, and health. Can. Psychol. 2008, 49, 182-185. [CrossRef]

20. Vallerand, R.J. Toward A Hierarchical Model of Intrinsic and Extrinsic Motivation. Adv. Exp. Soc. Psychol. 1997, 29, 271-360. [CrossRef]

21. Vallerand, R.J.; Losier, G.F. An integrative analysis of intrinsic and extrinsic motivation in sport. J. Appl. Sport Psychol. 1999, 11, 142-169. [CrossRef]

22. Ryan, R.M.; Plant, R.W.; O'Malley, S. Initial motivations for alcohol treatment: Relations with patient characteristics, treatment involvement, and dropout. Addict. Behav. 1995, 20, 279-297. [CrossRef]

23. Vansteenkiste, M.; Neyrinck, B.; Niemiec, C.P.; Soenens, B.; De Witte, H.; Van den Broeck, A. On the relations among work value orientations, psychological need satisfaction and job outcomes: A self-determination theory approach. J. Occup. Organ. Psychol. 2007, 80, 251-277. [CrossRef] 
24. Gagne, M. Autonomy support and need satisfaction in the motivation and well-being of gymnasts. J. Appl. Sport Psychol. 2003, 15, 372-390. [CrossRef]

25. Sheldon, K.M.; Kasser, T. Pursuing personal goals: Skills enable progress, but not all progress is beneficial. Personal. Soc. Psychol. Bulletin 1998, 24, 1319-1331. [CrossRef]

26. Markland, D.; Ingledew, D.K. Exercise participation motives: A self-determination theory perspective. In Intrinsic Motivation and Self-Determination in Exercise and Sport; Hagger, M.S., Chatzisarantis, N.L.D., Eds.; Human Kinetics: Champaign, IL, USA, 2007; pp. 23-34, 302-305.

27. Papaioannou, A.G.; Krommidas, C. Self-transcendence achievement goals and well-being. Int. J. Sport Exerc. Psychol. 2021, 19, 215-245. [CrossRef]

28. Fox, K.R. The effects of exercise on self-perceptions and self-esteem. In Physical Activity and Psychological Well Being; Biddle, S.J.H., Fox, K.R., Boutcher, S.H., Eds.; Routledge: London, UK, 2000; pp. 88-117.

29. Kernis, M.H. Toward a conceptualization of optimal self-esteem. Psychol. Inq. 2003, 14, 1-26. [CrossRef]

30. Arslan, G. Mediating role of the self-esteem and resilience in the association between social exclusion and life satisfaction among adolescents. Personal. Individ. Differ. 2019, 151, 109514. [CrossRef]

31. Bajaj, B.; Gupta, R.; Pande, N. Self-esteem mediates the relationship between mindfulness and well-being. Personal. Individ. Differ. 2016, 94, 96-100. [CrossRef]

32. Dogan, T.; Totan, T.; Sapmaz, F. The role of self-esteem, psychological well-being, emotional self-efficacy, and affect balance on happiness: A path model. Eur. Sci. J. 2013, 9, 31-42.

33. Lin, C.C. Self-esteem mediates the relationship between dispositional gratitude and well-being. Personal. Individ. Differ. 2015, 85, 145-148. [CrossRef]

34. Lin, C.C. Gratitude and depression in young adults: The mediating role of self-esteem and well-being. Personal. Individ. Differ. 2015, 87, 30-34. [CrossRef]

35. Li, B.; Pan, Y.; Liu, G.; Chen, W.; Lu, J.; Li, X. Perceived social support and self-esteem mediate the relationship between childhood maltreatment and psychosocial flourishing in Chinese undergraduate students. Child. Youth Serv. Rev. 2020, 117, 105303. [CrossRef]

36. Kazak Çetinkalp, Z.; Lochbaum, M. Flourishing, affect, and relative autonomy in adult exercisers: A within-person basic psychological need fulfillment perspective. Sports 2018, 6, 48. [CrossRef] [PubMed]

37. Telef, B.B. The Adaptation of psychological well-being into Turkish: A validity and reliability study. Hacet. Univ. J. Educ. 2013, 28, 374-384. (In Turkish)

38. Conroy, D.E.; Elliot, A.J.; Hofer, S.M. A $2 \times 2$ achievement goals questionnaire for sport: Evidence for factorial invariance, temporal stability, and external validity. J. Sport Exerc. Psychol. 2003, 25, 456-476. [CrossRef]

39. Kazak Çetinkalp, Z. Evaluation of Self-Determination Theory and Achievement Goal Theory. Ph.D. Thesis, Ege University, Health Sciences Institute, Izmir, Turkey, 2009. (In Turkish)

40. Guay, F.; Vallerand, R.J.; Blanchard, C. On the assessment of situational intrinsic and extrinsic motivation: The Situational Motivation Scale (SIMS). Motiv. Emot. 2000, 24, 175-213. [CrossRef]

41. Kazak Çetinkalp, Z. Psychometric properties of the Turkish version of the Situational Motivation Scale-SIMS. Türkiye Klin. J. Sports Sci. 2010, 2, 86-94. (In Turkish)

42. Marsh, H.W.; Richards, G.E.; Johnson, S.; Roche, L.; Tremayne, P. Physical Self-Description Questionnaire: Psychometric properties and a multitrait-multimethod analysis of relations to existing instruments. J. Sport Exerc. Psychol. 1994, 16, 270-305. [CrossRef]

43. Aşçı, F.H. The reliability and validity of PSDQ for Turkish population. In Proceedings of the 5th Sport Sciences Congress, Ankara, Turkey, 3-5 November 2000; pp. 122-123.

44. Marsh, H.W.; Asci, F.H.; Tomas, I.M. Multitrait-multimethod analyses of two physical self-concept instruments: A cross-cultural perspective. J. Sport Exerc. Psychol. 2002, 24, 99-119. [CrossRef]

45. Bentler, P.M.; Bonett, D.G. Significance tests and goodness of fit in the analysis of covariance structures. Psychol. Bull. 1980, 88, 588-606. [CrossRef]

46. Schermelleh-Engel, K.; Moosbrugger, H.; Müller, H. Evaluating the fit of structural equation models: Tests of significance and descriptive goodness-of-fit measures. Methods Psychol. Res. Online 2003, 8, 23-74.

47. Moller, A.C.; Elliot, A.J. The $2 \times 2$ Achievement Goal Framework: An Overview of Empirical Research. In Focus on Educational Psychology; Mittel, A.V., Ed.; Nova Science Publishers: New York, NY, USA, 2006; pp. 307-326.

48. Elliot, A.J.; Thrash, T.M. Approach-avoidance motivation in personality: Approach and avoidance temperaments and goals. J. Personal. Soc. Psychol. 2002, 82, 804-818. [CrossRef]

49. Adie, J.W.; Duda, J.L.; Ntoumanis, N. Achievement goals, competition appraisals, and the well- and ill-being of elite youth soccer players over two competitive seasons. J. Sport Exerc. Psychol. 2010, 32, 555-579. [CrossRef]

50. Tuominen-Soini, H.; Salmela-Aro, K.; Niemivirta, M. Achievement goal orientations and subjective well-being: A person-centred analysis. Learn. Instr. 2008, 18, 251-266. [CrossRef]

51. Kavussanu, M.; Harnisch, D.L. Self-esteem in children: Do goal orientations really matter? Br. J. Educ. Psychol. 2000, 70, $229-242$. [CrossRef]

52. Payne, S.C.; Youngcourt, S.S.; Beaubien, J.M. A meta-analytic examination of the goal orientation nomological net. J. Appl. Psychol. 2007, 92, 128-150. [CrossRef] 
53. Gagné, M.; Blanchard, C. Self-determination theory and well-being in athletes: It's the situation that counts. In Intrinsic Motivation and Self-Determination in Exercise and Sport; Hagger, M.S., Chatzisarantis, N.L.D., Eds.; Human Kinetics: Champaign, IL, USA, 2007; pp. 243-254, 353-355.

54. Ryan, R.M.; Deci, E.L. On happiness and human potentials: A review of research on hedonic and eudaimonic well-being. Annu. Rev. Psychol. 2001, 52, 141-166. [CrossRef] [PubMed]

55. Alvarez, M.S.; Balaguer, I.; Castillo, I.; Duda, J.L. The coach-created motivational climate, young athletes' well-being, and intentions to continue participation. J. Clin. Sport Psychol. 2012, 6, 166-179. [CrossRef]

56. González Olivares, Á.L.; Navarro, Ó.; Sánchez-Verdejo, F.J.; Muelas, Á. Psychological well-being and intrinsic motivation: Relationship in students who begin university studies at the school of education in Ciudad Real. Front. Psychol. 2020, 11, 2054. [CrossRef]

57. Weinstein, N.; Ryan, R.M. When helping helps: Autonomous motivation for prosocial behavior and its influence on well-being for the helper and recipient. J. Personal. Soc. Psychol. 2010, 98, 222-244. [CrossRef]

58. Sheldon, K.M.; Ryan, R.M.; Deci, E.L.; Kasser, T. The independent effects of goal contents and motives on well-being: It's both what you pursue and why you pursue it. Personal. Soc. Psychol. Bull. 2004, 30, 475-486. [CrossRef] [PubMed]

59. Deci, E.L.; Ryan, R.M. Human autonomy: The basis for true self-esteem. In Efficacy, Agency, and Self-Esteem; Kernis, M., Ed.; Plenum Press: New York, NY, USA, 1995; pp. 31-49.

60. Hein, V.; Hagger, M.S. Global self-esteem, goal achievement orientations, and self-determined behavioural regulations in a physical education setting. J. Sports Sci. 2007, 25, 149-159. [CrossRef]

61. Kernis, M.H.; Paradise, A.W.; Whitaker, D.J.; Wheatman, S.R.; Goldman, B.N. Master of one's psychological domain? Not likely if one's self-esteem is unstable. Personal. Soc. Psychol. Bull. 2000, 26, 1297-1305. [CrossRef]

62. Wilson, P.M.; Rodgers, W.M. The relationship between exercise motives and physical self-esteem in female exercise participants: An application of self-determination theory. J. Appl. Biobehav. Res. 2002, 7, 30-43. [CrossRef]

63. Valkenburg, P.M.; Peter, J.; Schouten, A.P. Friend networking sites and their relationship to adolescents' wellbeing and social self-esteem. Cyber Psychol. Behav. 2006, 9, 584-590. [CrossRef] [PubMed]

64. Rosenberg, M. Society and the Adolescent Self-Image, Rev. ed.; Wesleyan University Press: Middletown, CT, USA, 1989.

65. Fox, K.R. The Physical Self and Processes in Self-Esteem Development. In The Physical Self: From Motivation to Well-Being; Fox, K.R., Ed.; Human Kinetics: Champaign, IL, USA, 1997; pp. 111-140.

66. Shavelson, R.J.; Hubner, J.J.; Stanton, G.C. Self-concept: Validation of construct interpretations. Rev. Educ. Res. 1976, 46, 407-441. [CrossRef]

67. Craven, R.G.; Marsh, H.W. The centrality of the self-concept construct for psychological wellbeing and unlocking human potential: Implications for child and educational psychologists. Educ. Child Psychol. 2008, 25, 104-118.

68. Neff, K.D. Self-compassion, self-esteem, and well-being. Soc. Personal. Psychol. Compass 2011, 5, 1-12. [CrossRef] 